\title{
The fate of rock organic carbon in the Critical Zone
}

\author{
KATHERINE E. GRANT ${ }^{1 *}$, VALIER V. GALY ${ }^{2}$, ROBERT G. \\ HILTON $^{1}$ \\ ${ }^{1}$ Dept of Geography, Durham University, Durham, UK \\ (*correspondence: katherine.e.grant@durham.ac.uk) \\ ${ }^{2}$ Dept of Marine Chemistry and Geochemistry, WHOI, \\ Woods Hole, MA, USA
}

The rock organic carbon $\left(\mathrm{OC}_{\text {petro }}\right)$ reservoir is vast and contributes to the evolution of Earth's atmospheric $\mathrm{O}_{2}$ and $\mathrm{CO}_{2}$ concentrations over geological timescales[1]. There is an estimated $1100 \mathrm{Pg} \mathrm{C}$ stored as $\mathrm{OC}_{\text {petro }}$ in the upper $1 \mathrm{~m}$ of sedimentary rocks at the earth surface[2]. It has been shown that in rapidly eroding environments, chemical weathering of this $\mathrm{OC}_{\text {petro }}$ reservoir can rapidly release $\mathrm{CO}_{2}$ to the atmosphere[3]. However, $\mathrm{OC}_{\text {petro }}$ oxidation rates are poorly constrained, especially in more moderate erosion settings, where pedogenic processes control $\mathrm{OC}_{\text {petro incorporation into }}$ the modern terrestrial environment. Here we assess the fate of $\mathrm{OC}_{\text {petro }}$ during weathering in soils, as a function of the rock OC content, its thermal history (metamorphic grade), mineral matrix composition and its potential links to microbial consumption.

To do this, we quantify the thermal reactivity and isotopic composition of organic matter using Ramped Pyrolysis Oxidation (RPO) coupled to radiocarbon measurements (RPO- ${ }^{14} \mathrm{C}$ ). Using soils that have developed on a range of sedimentary rocks (grey shales, black shales, schists), we examine the distribution of both ${ }^{14} \mathrm{C}$ and activation energies, $\mathrm{E}\left(\mathrm{kJ} \mathrm{mol}^{-1}\right)$. Systematic evolutions of these distributions reveal chemical alteration of the $\mathrm{OC}_{\text {petro }}$ along bedrock to surface soils profiles, allowing to explore the role of $\mathrm{OC}_{\text {petro }}$ chemical oxidation or incorporation into modern biomass. By visiting sites with well-developed soil profiles and low erosion rates, these new data will allow us to assess whether any unaltered $\mathrm{OC}_{\text {petro }}$ can persist in soils and illuminate how this material interacts with its surrounding environment. [1] Berner, Lasaga \& Garrels (1983), Am. J. Sci., 641-683. [2] Copard, Amiotte-Suchet \& Di-Giovanni (2007), EPSL 258, 345-357. [3] Hemingway et al. (2018), Science 360, 209-212. 